\title{
Retention goaf stability influence comprehensive analysis on existing building
}

\author{
Deqing Gan ${ }^{1}$, Hongjian $\mathrm{Lu}^{1}$, Hui Lu², Haisheng Yu \\ ${ }^{1}$ College of Mine engineering, Hebei United University, Tangshan, Hebei, China \\ ${ }^{2}$ Tangshan Ralyway Vehicle CO.,LTD, Tangshan, Hebei, China \\ Luhongj2006@sina.com
}

Keywords: retention goaf, existing building, stability analysis, comprehensive analysis

\begin{abstract}
In order to study the stability influence of abandoned stope on existing surface constructions, this paper summarizes and analyzes the main controlling factors based upon one mine in Hebei province. This paper also details a qualitative and quantitative analysis utilizing the "Three Zones Theory" and "Movement Zone of Rock Theory". The results indicate that: a) Based on the "Three Zones Theory", a qualitative conclusion could be made that the empty stope area would result in surface deformation in certain range; b) Based on the "Movement Zone of Rock Theory", the safety of surface constructions would be affected, thus the empty stope should be treated in time. The paper has validated the feasibility of a proposed comprehensive analysis method on the stability influence of the abandoned stope on the existing surface constructions, and it also provides a scientific basis of emphasizing the necessity of treating the empty stope.
\end{abstract}

\section{Introduction}

Retention goaf is a huge complex structure excavation space which is accumulated in the process of recovery by mining companies because of not deal with on time[1-2]. Especially small and medium mining enterprises, poor ore body, production process rough, so it it easy to form a retention goaf.

Hebei province is one of the main iron ore producing areas, which is rich in iron mineral resources, because of high-intensity resource development for many years, the main iron ore producing areas in the formation of a large area of retention goaf. Not only to the exploitation of mining enterprises posed a serious security security risks, resulting in a large number of high-quality mineral resources not used effectively, but also remain empty areas to increase over time will cause collapse of overlying rocks, causing ground movement, ultimately affect the stability of the surface construction of building, to the disastrous consequences caused to nearby residents, a serious threat to people's lives and property, affect social harmony and stability. It is essential to the theoretical analysis, make quantitative and qualitative analysis to the stabilizing influence of retention goaf and surface buildings., in order to protection of life and property around mining areas and the safety of buildings.

The impact on Collapse of overlying strata and ground movement prediction and the mining of the building damage and other issues, coal companies have done a lot of work and concluded a lot of useful experience and achievements. Metal ore mining methods for different geological conditions and coal, based on the proposed coal strata and Prediction of Surface Movement is generally difficult for metal mines[3-4].

This article make a mine in Hebei for example, analized the main elements impacted on the stability of empty areas, This paper also details a qualitative and quantitative analysis utilizing the “Three Zones Theory”and "Movement Zone of Rock Theory”.

\section{Stability Factors of retention goaf}


Effective mining height[5]. Height in the greater the height of overburden is greater. When using hierarchical method of mining, the more layer, the high of caving zone and fracture zone growth smaller.

Roof Management. When using caving method, the maximum damage on the overlying rock; filling method is generally used without risk of cracking down, even if there is fell, its height is very small.

Lithology[6]. Overlying rocks hard, brittle, the overburden rock height and large; overlying rock is soft rock, plasticity good, the small height of overburden failure.

Rock properties. Rock properties, especially thephysical and mechanical properties is one of the main factors that affect the empty areas stability and rock out. Rock particularity and complexity is the main reason of complicate rock mass movement issue.

Orebody dip. Ore body of different angle has different effects on the empty areas. Gob volume under the same conditions, per unit area, steep than the gently inclined on the surface of the destruction of the region play a role more focused, and easier to cut into the destruction of the vertical plunger. When the loose bodies with same compression ratio, larger inclined ore body mined area is not easy to remain stable, loosed body easily constantly moving down and caving with the constantly moving down mining or caving with mining declined. It is one of the reasons caused the ground constantly settlement.

Mining depth, cavity size and existing time. Most inclined thin ore group is in mountainous terrain and exposed surface. Mining surface movement caused by an empty area with intensive mining depth and pulse groups hase different characteristic. Pulse groups sparse, pulse spacing greater than $20 \sim 30 \mathrm{~m}$, when shallow mining depth and a certain number of empty areas supporting pillar, the rock mass caused by the exploitation of surface subsidence phenomena involving less; Pulse group intensive and mining depth increases, it can cause large-scale mass movement and to surface damage.

In addition, a variety of rock structures (faults, level, broken belt, etc.) formed by the weak lower surface of the rock mass strength. Weak surface geological structure there is considerable degree of influence the development of rock mass, control the scope of its development.

\section{The evaluation method on retention goaf stability}

"Three zones theory" qualitative evaluation. Ore mining destructed the original balance of the stress field, stress distribution to be re-balanced, leading to gob in motion on the formation of overlying strata caving zone, fracture zone and the bending band.

The caving zone[7].The roof due to the impact of ore mining, close to the overburden above the ore crushing and falling of the area known as the caving zone, run behind the play of broken rock is not caving of overlying strata supporting role. The following empirical formula often used to calculate the height of the caving zone:

$$
h=\frac{m}{k-1}
$$

In the formula: $\mathrm{m}$ —goaf height, $\mathrm{k}$ —coefficient of loose rock,generally1.25 1.50.

The fracture zone. Above the caving zone is fractured zone, the sinking of the rock band bending, deformation is large, the rock split along the bedding forming separation, and under the action of tensile stress in a large number of vertical cracks in the rock, making the rock in the band lost its original integrity.

The bending zone.The rock above fracture zone only appears sink bending, and show overall movement, called the bending zone or the overall mobile belt. The band rocks generally not broken, only in the law of gravity to bend under the action, so the rock is better to maintain the integrity of the original

Sum of the above three zones to be formed gob deformation zone. According to deformation with height and depth of the relationship between the ore body to determine whether an empty area on the surface deformation caused. 
Qualititave evaluation methods of rock moving zone.It was forming goaf after mining underground ore body, hanging adit layer and angle was steed relatively, footwall rocks under the effect of overlying strata and deadweight, Gradually deformed, mobiled and caving, and extended to the upper part, when the gob after expanding to a certain extent, this process evolved to the surface, forming a fall area. From underground mining, formating mined areas, as the same time, because of rock movemented, formed mobile belt in a certain range. Engineering and buildings within a range of movementing are likely to suffer from deformation and failure [8]. Usually use of rock hanging adit layer and footwall rocks or subcidence angle to determine the extent of deformation and failure of rock.

Using this method qualitative evaluation the impact damage of an empty area on the surface buildings, which is simple, practical, intuitive and clear. But because of complicated geological conditions, it is difficult to determine the angle and movement angle of fall.

\section{Project background}

This paper based on four Qi Ying mining areas of Hebei Cheng de , Qi Ying four mining area started construction in 2005, put into operation in 2006, the main ore body mining Fe23, There are two mining ore body, It has been mined $346 \mathrm{~m}$, 323m and 303m three middle parts at 2010, mining method is belong to stope method, it is a tunnel ripping-type stope , transport within the roadway layout in the vein, tunnel is stope, mining height of about $10 \mathrm{~m}, 10 \mathrm{~m}$ high columns around the top.

Qi Ying four mining area was constructed in 2005 when the ground situation is simple, no buildings and the railways, roads and other facilities around it, in 2007, the construction of the railway in the mining area at the south side of about 100 meter. Later gradually building a rural road, Zhou Village Park stage, mine offices, staff quarters, Zhou table village cultural centers, hotels table Zhou, Zhou and other public facilities in primary stage, in which weekly table Village Park, mining offices, staff quarters, weeks Table village cultural centers, hotels table Zhou, Zhou table primary school and other buildings. After years of mining exploration, formation of a certain area of the mined area, although currently no gob caving phenomenon, But with the gob exposure time increases, ground pressure will gradually increased, each shaft and surface gradually threat the safety of buildings. Therefore it is necessary to details stability analysis and evaluation and existing mined area of building structures on surface, it was provide a theoretical basis to deal with retention goaf.

\section{Stability analisis}

“Three Zones Theory” qualitative evaluation. Take use of formula (1) to estimate the height of the caving zone. According to mining stage height, height to take gob $10 \mathrm{~m}$, the height of the caving zone in $20 \sim 40 \mathrm{~m}$.

Fracture zone with a similar height with caving zone. The height of ore fractured iron ore is about $20 \sim 40 \mathrm{~m}$.

The height of bending zone was as 5 times as the height of fractured zone, the empty area in the formation of highly curved between $100 \sim 200 \mathrm{~m}$.

With the sum of the above 3 zones, the height of the iron ore mined area deformation was between $140 \sim 280 \mathrm{~m}$.

The level of iron ore mined in the border $346 \mathrm{~m}$ gob formed from the ground about $100 \mathrm{~m}$ depth in general, we can see that the mine will cause the existing mined area within a certain range of ground deformation.

Rock movement zone qualitative evaluation. According to the actual geological conditions of mine to make sure that the range of rock movement of goaf by $65^{\circ}$, delineation of the lower plate by $70^{\circ}, 75^{\circ}$ determined at end, ultimately determine the range of movement of rock mined areas, as shown in Fig.1. 


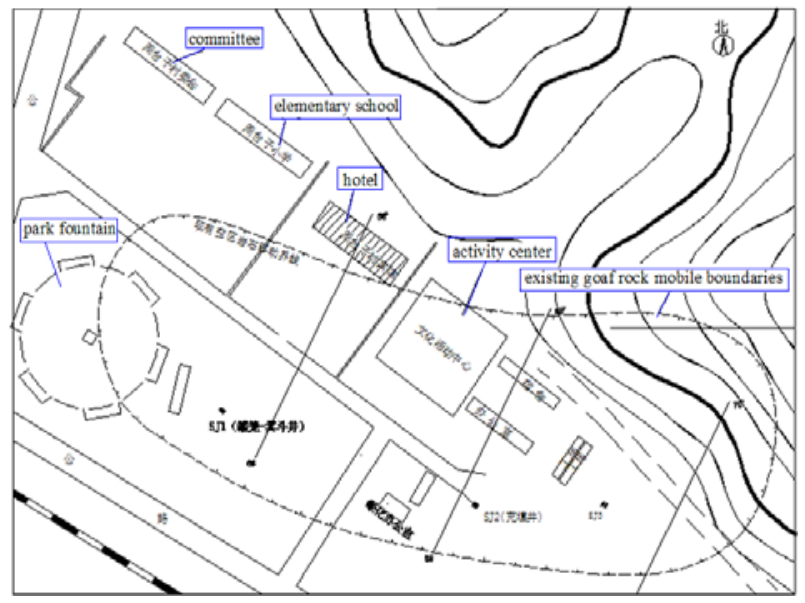

Fig.1 rock movement zone of existing goaf

According to the range of rock movement zone of existing goaf of current mining can be seen, cultural centers, mining shafts, and some facilities of the gardens are in the range, we can see the existing goaf is threat to the safety of the ground building construction.

\section{Summary}

This paper based on analyzed the stability factors of retention goaf and evaluation the method. Make a stability analysis of surface building to the Hebei Chengde Qi Ying four mining areas.

According to the "three zones theory" qualitative evaluation, the height of existing goaf deformation between $140 \sim 280 \mathrm{~m}$, The first layer of mine roof cavity is generally $100 \mathrm{~m}$ depth from the ground around, the existing mine goaf cause a range of ground deformation.

According to the qualitative evaluation of the rock movement zone concluded that center of cultural activities, mine shafts, and some of the facilities of gardens all are in the range, Gob existing goaf will threaten the security of building on the ground.

In summary,we use three zones theory and rock movement theory, details qualitative and quantitative analysis to the stability of mining retention goaf and the building on the surface, and obtain satisfactory results. The results provide a scientific basis. were stranded in the mine's processing of mined areas need to deal with mine retention goaf.

\section{References}

[1] ZHAO J G, SUN Z D, ZHANG Z P. Analysis ofmulti-m ined-out area of the collapse $\mathrm{m}$ echanism and developm ent factor.Ground water, Vol.32(2010),p.158

[2] GAO F, ZHOU K P,DONG W J.Similar material simulation of time series system for induced caving of roof in continuous mining under back fill.Journal of Central South University of Technology, Vol.15(2008),p.356

[3] ZENG K H,ZHANG G F, YANG X J. Review on stability and deforma tion prediction of ground base underlying multi-layer goaf in mentougou area. China Mining Magazing, Vol.19(2010),p.87

[4] LIU B W. Relationship between height of "three zones" and lithology in overlying strata in mining yard Coal Technology, Vol.28(2009),p.56

[5] WU Z Y,BO J S,DU G L. Effects of mining excavation on ground stability. Journal Of Natural Disasters, Vol.13(2004),p.140

[6] ZHANG A B, LIU X X,GAO J X. Law of time-dependent deformation and chaos characteristics of goaf surface based on empirical mode decomposition and phase space reconstruction technique. Rock and Soil Mechanics, Vol.31(2010),p.3191

[7] ZENG K H,ZHANG G F, YANG X J. Review on stability and deforma tion prediction of ground base underlying multi-layer goaf in mentougou area. China Mining Magazing, Vol.19(2010), p.87 
[8] SUN Z F. The research of numerical simulation for the movement and damage's regulation of overburdened rock, mass ith old goaf under loads. Journal of North China Institute of Science and Technology, Vol.7(2010),p.17 